\title{
Plantão Psicológico Gestáltico - A Escrita de uma Experiência
}

\section{Gestaltic Psychological Duty - The Writing of an Experience \\ Deber Psicológico Gestáltico - La Escritura de una Experiencia}

\author{
Luciana Loyola Madeira Soares* \\ Centro Universitário Celso Lisboa - UCL, Rio de Janeiro, Rio de Janeiro, Brasil
}

\begin{abstract}
RESUMO
Apresento a escrita de minha experiência de criação do campo de estágio em Plantão Psicológico fundamentado na Abordagem Gestáltica num curso de graduação em Psicologia numa Instituição particular de Ensino Superior no Rio de Janeiro. Sendo escassa a literatura gestáltica neste tema, recorri a autores baseados em Carl Rogers, em cuja abordagem há farta oferta de publicações, o que me permitiu criar boas conexões com autores da Gestaltterapia. Chamei para compor esse diálogo autores da Psicologia Social e, assim, proponho o único atendimento no Plantão Psicológico Gestáltico como uma prática de clínica ampliada que pró-move deslocamentos nos fazeres acadêmicos na graduação em Psicologia por expandir as práticas clínicos na clínica-escola para além da psicoterapia bipessoal e por propor a sensibilidade como condição de encorpamento ético nos fazeres psicológicos. Finalizo, indicando o Plantão Psicológico Gestáltico como uma prática política e inclusiva, portanto, democrática, contemplando contemporaneamente a demanda por atenção psicológica pontual, em diferentes espaços e contextos - fomentando atenção especialmente à nossa formação universitária.
\end{abstract}

Palavras-chave: plantão psicológico gestáltico, práticas sensíveis em clínica-escola, graduação em psicologia.

\begin{abstract}
I present the writing of my experience of creating the field of internship on Psychological Duty based on the Gestaltic Approach in a graduation course in Psychology in a private Institution of Higher Education in Rio de Janeiro. Being the gestalt literature scarce on this subject, I have resorted to authors based on Carl Rogers, in whose approach there is a large supply of publications, which allowed me to create good connections with Gestalttherapy authors. I called authors of Social Psychology to compose this dialogue and so, I propose the only service in the Gestaltic Psychological Duty as an expanded clinic practice, which promotes displacements in the academic studies in Psychology by expanding clinical practices in the clinicschool beyond bipersonal psychotherapy and for proposing sensitivity as a condition of ethical embodiment in psychological studies. I conclude by indicating the Gestaltic Psychological Duty as a political and inclusive practice, therefore, democratic, contemporaneously contemplating the
\end{abstract}


demand for punctual psychological attention, in different spaces and contexts - fostering attention especially to our university education.

Keywords: gestaltic psychological duty, sensibility in the practice at the clinic-school, graduation in psychology.

\begin{abstract}
RESUMEN
Presento mi experiencia en la creación de la pasantía sobre el Deber Psicológico basada en el Enfoque Gestáltico en un curso de graduación en Psicología en una Institución de Educación Superior privada en Rio de Janeiro. Como hay poca literatura gestáltica sobre este tema, he recurrido a autores basados en Carl Rogers, en cuyo enfoque hay una gran oferta de publicaciones, lo que me permitió crear buenas conexiones con los autores de la terapia Gestalt. Llamé a los autores de la Psicología Social para componer este diálogo y así, propongo el único servicio en el Deber Psicológico Gestáltico como una práctica clínica expandida, que promueva desplazamientos en los estudios académicos de la Psicología para expandir las prácticas clínicas en la clínica-escuela más allá de la psicoterapia bipersonal y para proponer la sensibilidad como condición de incorporación ético en los estudios psicológicos. Concluyo señalando el Deber Psicológico Gestáltico como una práctica política e inclusiva, así que democrática, que contempla la demanda de atención psicológica puntual, en diferentes espacios y contextos - fomentando la atención especialmente a nuestra educación universitaria.
\end{abstract}

Palabras clave: deber psicológico gestáltico, sensibilidade en la práctica en la clínica-escuela, graduación en psicología.

Sou supervisora do Serviço de Psicologia Aplicada (SPA) de uma Instituição de Ensino Superior (IES) privada há muitos anos, tendo sob minha responsabilidade equipes de estágio em Psicologia Clínica na Abordagem Gestáltica. No cotidiano da docência e das supervisões, venho problematizando as desistências de continuidade das pessoas que se inscrevem para atendimento psicológico com as seguintes indagações: teria mesmo $x^{1}$ cliente necessidade de dar prosseguimento?; será que muitxs dxs inscritxs para atendimento psicológico necessitam ou desejam psicoterapia?; o que as pessoas querem e esperam de um atendimento psicológico?; a única vocação das práticas em Psicologia clínica do SPA é a psicoterapia?; o SPA estaria efetivamente funcionando como um espaço de acolhimento?

Juntamente com as coordenações do curso de Psicologia e do SPA, e com outrxs supervisorxs, vim acompanhando a necessidade de se reconfigurar a 'porta de entrada' para xs candidatxs a clientes de atendimento psicológico.

Tendo sido responsável pela disciplina Psicoterapias e Aconselhamento Psicológico, constatei a importância de preparar xs alunxs para a prática do atendimento psicológico, que é bem pouco valorizada, apesar de ser legalmente exclusiva dx psicólogx no Brasil. De acordo com Schmidt (1987), o aconselhamento psicológico começa com Rogers, ainda com objetivos normativos, centrado no forte poder do especialista, visando promover ajustamentos das 
pessoas ao meio através de aprendizagem. Rogers saiu do foco no problema, para o foco na pessoa; das ferramentas de avaliação, para a relação entre psicólogx e cliente; do foco nos resultados, para o foco nos processos. Rogers trouxe 0 conceito de 'tendência atualizante', como a crença na permanente tendência humana ao crescimento e ao desenvolvimento, o que norteia as intervenções nas práticas de atendimento psicológico. Ainda de acordo com Schmidt, o aconselhamento psicológico se afastou do modelo pedagógicocorretivo e se aproximou da clínica sem ser um modelo médicocurativo. Schmidt (1987) aponta que o atendimento psicológico deve ser conduzido como uma facilitação da habilidade de viver e traduzir em palavras e gestos as atitudes básicas num encontro, problematizando os modos de compartilhar poder, controle e decisão. A autora aponta que a proposta rogeriana é política por encaminharse pela atenção ao modo como cada pessoa lida com poder, controle e tomada de decisão sobre xs outrxs e sobre si mesma. Ela acrescenta que Rogers afastou-se das teorias da personalidade e de psicopatologia, preferindo que cada uxx elabore suas próprias hipóteses sobre os fenômenos psicológicos e interpessoais, através da experienciação vivenciada nos encontros. Assim, Rogers ampliou as práticas das relações de ajuda.

Em 2018, propus um campo de práticas em que xs estagiárixs ficassem distribuídxs em blocos de horários durante a semana, para acolherem imediatamente os pedidos de atendimento em caráter de urgência, assim como ficarem à disposição dxs candidatxs que viessem se inscrever por indicação ou por encaminhamento institucional externo - as emergências. Para viabilizar esse campo de prática, adotei a produção de conhecimento de autorxs brasileiros que se dedicam ao tema do Aconselhamento Psicológico e do Plantão Psicológico, que quase em sua totalidade são da Abordagem Centrada na Pessoa - ACP. Articulo essa prática clínica com uma prática de pesquisa em Psicologia Social, alicerçada em autorxs brasileirxs que trabalham a produção de conhecimento nas conexões CTS - Ciência, Tecnologia e Sociedade - o que consiste em dar aos fazeres em Psicologia, efeito reticular e político. A atitude dxs pesquisadorxs como parte do campo, em simetria com x pesquisadx, permite-nos não só coletar dados, mas também produzir uma Psicologia em que teorias e práticas fazem-se mutuamente - xs estagiárixs estarão aprendendo e produzindo conhecimento em prol do SPA e de uma formação política em Psicologia; conhecimento encorpado em suas próprias experiências de fazer Plantão $\operatorname{COM}^{2}$ xs demais actantes envolvidxs nos processos relacionais e institucionais que tecem esse campo de estágio: clientela atendida, colegas de outros campos de estágio, recepcionistas do SPA, etc. Assim, estamos num campo de estágio que seja simultaneamente um campo de pesquisa, articulando os conteúdos teóricos da já referida disciplina curricular e, 
portanto, em consonância com as Diretrizes Curriculares vigentes para o curso de graduação em Psicologia no Brasil.

\section{Procedimentos de estágio}

O Plantão pode ser efetuado em no mínimo um e no máximo três atendimentos (medida flexível, dependendo da situação). A ideia é que $\mathrm{x}$ alunx, ao proceder ao atendimento, esteja disponível para o acolhimento às condições e necessidades manifestadas pelx cliente no momento. Considero importante verificar a clareza da pessoa acerca da queixa que apresenta ao(à) estagiárix, que é orientadx a disponibilizar-se à compreensão do que é trazido pelx cliente e apresentar-Ihe seu entendimento para uma possível conscientização de sua situação atual. É necessário verificar com a pessoa que pede atenção, se ela tem noção de seu pedido: atenção? Ajuda? Para quê? Como? Verifica-se se, da parte $\mathrm{dx}$ atendidx, há interesse de que se estabeleça algum encaminhamento que contemple sua necessidade: se, para algum dos campos de estágio do SPA ou para serviço externo. $O$ material produzido sobre $O$ atendimento fica posteriormente à disposição $\mathrm{dxs}$ demais supervisorxs para continuidade de atendimento. Assim, o Plantão volta-se também para dar suporte a pessoas que cheguem precisando de acolhimento imediato ou em mais de um atendimento, enquanto aguardam por inclusão em uma das equipes de psicoterapia.

\section{Algumas provocações, indagações e inquietações que o único atendimento faz}

Observo que a formação universitária dx futurx psicólogx contempla menos a prática do atendimento psicológico, do que as práticas das psicoterapias. Defendo que o único atendimento precisa ter seu valor destacado, num contexto em que a psicoterapia é hegemônica. É também importante não confundir com psicoterapia breve. Sobre a sessão que se fecha em si mesma, Campos e Daltro (2015) relatam uma experiência de Clínica Ampliada em supervisão de estágio gestalticamente orientada. As autoras contribuem para elucidar a relevância de práticas psicológicas na graduação que problematizam os padrões rotineiros e propõem atitudes criativamente desafiadoras:

Muitas vezes nestes encontros emergenciais alunos encontraram clientes em crise aguda e utilizaram-se de metodologias para trazê-los de volta a um equilíbrio, como a respiração, enraizamento, organização de ideias e sentimentos. Muitas vezes o trabalho foi de ajudar o cliente a sair da crise e 
poder alcançar um nível de integração que o permitisse focar melhor nas suas necessidades e levar adiante seu próprio desenvolvimento.

Algumas sessões foram únicas, e em outros casos com retorno de até três vezes. Porém, cada sessão era fechada em si mesma, como se fosse a última, e buscava-se atender ao próximo passo de cada tema aberto. O terapeuta era ouvinte ativo, através da escuta profunda ajudando a pessoa a conduzir o próprio processo. Enfim ficou enfatizada a necessidade do estagiário de saber ouvir, estar presente, congruente, poder afinar o foco do trabalho e oferecer uma escuta que organizava as questões do cliente. (Campos \& Daltro, 2015, p. 66).

É interessante constatar que as autoras fazem nesse trecho uma menção a 'terapeuta' como a praticante do único atendimento. Essa referência convoca a debates e desdobramentos quanto ao papel $\mathrm{dx}$ profissional (ou estagiárix) de Psicologia que se dedica a práticas clínicas não psicoterapêuticas. Discordo de que, ao fazer um atendimento psicológico - único ou não - estejamos fazendo uma psicoterapia curta, breve ou focal. Trago a contribuição de Tassinari e Durange (2019):

. . . o atendimento no plantão dispensa mediadores, a consulta não tem duração predeterminada, não é necessário agendar previamente, a pessoa pode ser atendida por profissionais diferentes, 0 atendimento não implica em continuidade, 0 plantonista interessa-se por qualquer material (e não apenas por conflitos psicológicos) e mantém-se presente no presente, pois não conta com os próximos atendimentos. (p. 13).

Os autores pensam o Plantão Psicológico como: ". . . um atendimento que tem no encontro o seu eixo principal e, assim, pode ocorrer em qualquer tempo e duração e em qualquer local e contexto." (Tassinari \& Durange, 2019, p. 29).

Várias são as indagações que vêm quando estudamos o atendimento psicológico efetuado numa única vez: o único atendimento é só um desabafo?; tem efeito terapêutico?; em Psicologia, só tem valor o que é terapêutico?; como receber e lidar com a urgência daquelx que vem para ser atendidx?; como é seu pedido por cuidado, atenção, escuta?; por ser um atendimento sem o estabelecimento de contrato de continuidade, é superficial?; menos relevante?

Rebouças e Dutra (2010) desenvolvem uma revisão bibliográfica sobre o Plantão Psicológico, na perspectiva fenomenológicoexistencial, como prática clínica adequada às condições contemporâneas de vida humana. As autoras apresentam 0 comprometimento do psicólogo com o outro, em quaisquer situações, 
sendo a abertura ao novo e ao diferente, atitudes indispensáveis ao acolhimento e compreensão do sofrimento do sujeito contemporâneo em suas formas de existir.

O que significa compreender esse outro a partir da experiência e dos significados que ele atribui ao mundo, levando em consideração o contexto no qual está inserido, considerando-o como um ser-no-mundo e, portanto, constituído por este, ao mesmo tempo em que o constitui.

Dentro dessa perspectiva contemporânea, tem-se falado numa nova modalidade clínica que veio não substituir a psicoterapia, mas se constituir numa alternativa a esta; na verdade, trata-se de uma prática que se adequa às demandas atuais, e nomeada por Mosqueira, Morato e Noguchi (2006) como uma prática de atenção psicológica. (Rebouças \& Dutra, 2010, p. 20).

Rebouças e Dutra (2010) propõem o psicólogo clínico contemporâneo como um "profissional do encontro" (p. 21). As autoras afirmam que a ética desta clínica é a do encontro pelo cuidado, não pelas técnicas.

A clínica comprometida com a emergência de novos sentidos e com a singularidade tem a obrigação de ousar, arriscar, inventar, enfim, de estar sempre em movimento e em permanente construção. Assim, não pode estar circunscrita em um único saber ou ser compreendida a partir de uma única lógica. A contemporaneidade tem demandado da clínica uma postura multi e transdisciplinar diferentemente do que ocorria na modernidade. (Rebouças \& Dutra, 2010, p. 22).

Portanto, 'clínico' é um modo de fazer, não um adjetivo para qualificar um campo de práticas diversas. Num tempo de remédios e soluções centradas nas técnicas, no imediatismo, no individualismo e no especialismo, 0 atendimento psicológico vem fazer o resgate da noção de relação de ajuda psicológica pontual, através da oferta de atenção. O pedido por atenção precisa ser acolhido como algo, muitas vezes indizível, que nem sempre é uma clara verbalização de pedido de ajuda. A respeito de 'ajuda', em Morato (1987) encontramos:

Mas por que esse termo 'ajuda'? Por que não simplesmente referir-se a inter-relações pessoais? . . . seriam todas as relações interpessoais, relações de ajuda?

Ao pensar em relação, imediatamente ocorre a imagem de um entrelaçamento, uma ligação entre dois elementos. Da mesma forma, ao falar em relação de ajuda pressupõe-se um elemento que necessita de algo e vai buscá-lo em outro que está disposto a oferecer o que o primeiro precisa. . . . ajudar não 
significa necessariamente dar ao outro exatamente o que ele precisa. . . . ajuda significa favorecer ao outro as condições necessárias para seu desenvolvimento.

. . Pergunto-me se não seria exatamente essa a ideia de ajuda: oferecer-nos à disposição, mas contando com o esforço do outro para que ele nos ajude a ajudá-lo; oferecer-nos como um meio, para que através dessa relação mantida conosco, o indivíduo encontre modos de viabilizar seu processo de ajuda. (p. 24-25).

Mais adiante, a autora salienta que entende 'ajuda' como experiência relacional que promove crescimento e desenvolvimento. Com isso, afirma que é preciso marcar que nem todas as relações comumente chamadas de 'ajuda' efetivamente promovem crescimento e mudança.

. . . uma informação bem colocada na entrevista de ajuda pode facilitar a percepção de um caminho para o cliente e este se dá por satisfeito naquele momento específico e para aquele caminho específico; não quer expandir-se mais. Nem sempre é terapia que o cliente vem buscar como ajuda. . . . ajudamos, facilitamos, mas nem sempre podemos determinar se os objetivos foram ou não alcançados. É muito gratificante oferecer ajuda, mas levando em conta que a direção dessa ajuda não nos pertence. (Morato, 1987, p. 27).

Voltando a Schmidt (1987): "Do ponto de vista de uma entrevista de ajuda, o principal é receber o cliente e facilitar para que ele se posicione diante de seu sofrimento psíquico." (p. 16). A autora indica mais adiante, que depende de como o cliente configura para si na relação com o psicólogo, se o pedido de ajuda será de psicoterapia ou não.

Tassinari e Durange (2019) apontam que:

. . . a clínica da urgência psicológica conforme a entendemos, . . . é uma clínica da radicalidade do encontro, que tem emergido através dos atendimentos no plantão psicológico. Neste sentido, um encontro pode ser suficiente para deflagrar mudanças e perspectivas promovendo o movimento contínuo da saúde. (p. 28).

Nem todas as pessoas que buscam atendimento por psicólogx pretendem permanecer. No entanto, a formação universitária de estudantes de Psicologia fomenta a ideia de que a busca pelx psicólogx é necessariamente a busca por psicoterapia, expectativa que vale também para xs candidatxs à graduação em Psicologia - a 
maioria demonstra, em inequívocas verbalizações, entrar para a graduação em Psicologia para ter consultório e trabalhar como psicoterapeutas. Muitxs até ignoram que à(ao) psicólogx cabe atuar em outras atividades profissionais. A noção de descontinuidade parece banida como possibilidade no cenário dos fazeres psicológicos. Defendo que esta é uma noção que merece atenção, podendo ser acolhida e ser escutada como uma voz de nosso tempo. Tassinari e Durange (2019) problematizam o tema da descontinuidade - tanto dxs clientes quanto dxs psicólogxs - como cercado de preconceitos e noções naturalizadas na prática da clínica psicológica:

. . os clientes que abandonam, geralmente são descritos pelos pesquisadores como 'resistentes' ou 'personalidade border line', ou 'eles não estão prontos para a psicoterapia', ou 'eles não têm motivação para a mudança', ou 'estão inclinados a negar sua doença'. Psicoterapeutas que abandonam os clientes são descritos como 'menos experientes' ou 'mais etnocêntricos', 'menos pessoal' ou 'carente de calor', etc. (p. 45).

Afirmo que o que fazemos no único atendimento não é adotar uma atitude de confiança em sua condição de expressar satisfação com o que viveu ao sentir-se sendo ajudadx pontualmente naquele atendimento psicológico, que se constituiu numa experiência relacional única ${ }^{3}$. Concordo com Freire (2003) que afirma que $x$ psicólogx, ou $x$ estudante de Psicologia, observando a transitoriedade da condição no atendimento psicológico:

. . . deve, portanto, oferecer minimamente essa serenidade, mas sem que se transforme em uma falsa segurança que impede o cliente de ver-se, em sua finitude, habitando a tragicidade do mundo. Morada temporária, eu diria, enquanto o cliente (re)constrói sua própria habitação. Hospitalidade oferecida ao habitante de um mundo inóspito. (p. 14).

\section{Plantão Psicológico Gestáltico}

Em outro trabalho (Soares, 2019), pensando a abordagem gestáltica como prática política, como modo de resistir aos desafios da contemporaneidade, recorri a Buber (2017), para quem a crise do sujeito contemporâneo consistia em não saber lidar com o que criou:

A inspiração em Buber me renova as forças para um cotidiano desafiador, no entanto, segui-lo é igualmente desafiador. . . . para uma efetiva prática dialógica, não dá para apenas falar sobre a dialogicidade sem vivê-la. Uma prática psicológica 
dialogicamente buberiana é mutuamente responsável, comprometida, solidária, confirmadora, humilde e inclusiva. É fundamentada nos Encontros, na presença que produz sentidos. (Soares, 2019, p. 101).

Numa busca na literatura gestáltica, os textos que encontrei têm sido valiosos e fundamentais para a construção do projeto e da prática do plantão, no entanto, abriram-se outras indagações: como organizar um campo de estágio fundamentado na abordagem gestáltica, sem apoio bibliográfico?; o que significa acolher gestalticamente?; como Gestalt-terapeutas, temos problematizado o que é Atendimento Psicológico, ou só nos dedicamos à prática da psicoterapia?

Acessei uns poucos trabalhos gestálticos, em raras apresentações em congressos, fazendo breve referência ao Plantão Psicológico Gestáltico em meio a outros temas e práticas do campo da Clínica Ampliada. Num antigo texto, Guedes et al. (1981) relataram a criação do espaço de acolhimento Kairós, proposta gestáltica de acolhimento pontual que antecipou a noção de clínica ampliada e de despatologização. Desde então, não tive acesso a outra iniciativa como essa, que se dedicasse ao estudo daquilo que Abel e seu grupo chamaram de 'consulta avulsa'. A meu ver, essxs autorxs anteciparam, na Consulta Avulsa, o que hoje chamo de Plantão Psicológico Gestáltico.

A CONSULTA AVULSA [grifo dxs autorxs] é, portanto, um atendimento voltado para o momento atual de vida de cada um, visando assessorar situações específicas e contextualizadas, diferenciando-se da psicoterapia, que é um processo voltado para a dinâmica psicológica da pessoa. Tem como alvo o indivíduo que está [grifo dxs autorxs] com problemas e não o problemático, destinando-se desta maneira, à pessoa que está atravessando crises, enfrentando conflitos no trabalho ou com a família, sentindo necessidade de esclarecimentos, orientação ou encaminhamento, passando por um momento de tomada de decisão ou também momentos onde sinta necessidade de confidenciar seus problemas. (Guedes et al., 1981, p. 61).

Xs autorxs, mais adiante, salientam que não se interessam só por problemas pontuais e dedicam-se ao único atendimento em perspectiva não explicativa, não causalista, não classificatória, não preditiva, não patologizante, portanto:

Lidamos com a atitude da pessoa frente a seu problema, acompanhando suas interrupções, seus significados, detectando possíveis Gestalten fixas, num movimento que vai dando 
contexto, contorno, fundo à figura em questão, que então, adquirindo nitidez, propicia condições para uma ressignificação e uma reorganização. (Guedes et al., 1981, p. 61).

A prática do Plantão Gestáltico apresenta-se como um modo de acolhimento à queixa, ao pedido de atenção, em que a reconfiguração da experiência de atender e de ser atendidx protagoniza a situação clínica. Priorizamos a psicologia do 'entre' (Soares, 2017), da mutualidade, em detrimento da psicologia dx 'outrx'. Nossa proposta clínica, portanto, consiste em aprendermos cotidianamente a fazer daquele único atendimento, um atendimento único.

$\mathrm{Na}$ perspectiva gestáltica, interessamo-nos pelo que a pessoa percebe de sua condição atual, como vem lidando com o que a aflige, de que recursos vem dispondo para agir criativamente. $O$ modo como $x$ cliente lida com seus conflitos, ou com a queixa que apresenta, serve de sinalização para quem $x$ atende, quem $x$ acompanhará na formulação da awareness possível para o momento. Trabalhamos gestalticamente na perspectiva da autorregulação, entendendo as crises como a emergência de gestalten abertas que buscam por fechamento.

O Plantão Gestáltico vem performando uma realidade de estágio que promove deslocamentos nxs alunxs de Psicologia, convocando-xs a problematizarem sua prática clínica e sair da $f(\hat{o}) r m a$ acadêmica (Soares, 2009) que tradicionalmente xs coloca engessadxs em condutas pautadas em classificações, prognósticos e noções de origem médica, como 'alta' e 'cura'. Xs estagiárixs vêm sendo provocadxs a perceberem-se como fazedorxs de Psicologia, comprometidxs com o respeito à diversidade dos modos de existir e com a multiplicidade de pedidos que chegam até elxs neste campo de estágio. Sendo a Abordagem Gestáltica pautada na mútua afetação, é importante assinalar o quanto esses descentramentos, provocações, convocações e problematizações afetam o grupo de estagiárixs, e que suas dúvidas, desconfortos, surpresas e curiosidades vêm marcando seus percursos. Como supervisora, dedico-me a criar condições para que o estágio seja alicerçado em sensibilidades para ouvir, ser ouvido, ver, ser visto, para que exercitemos o mútuo suporte nessa travessia de aprendizagens, travessia que é vivência tanto singular, quanto coletiva. Nossas supervisões constituem-se em momentos vivencialmente únicos, transformadores para todxs que ali estão tempo de partilha de sofrimentos, medos, impotências, inseguranças, encorajamentos, apoios, compreensão, ajuda, vibração de alegria com os crescimentos, com os relatos, com as falas dxs atendidxs.

Destaco alguns alertas que a querida Laura Quadros (2014) nos faz, quanto ao que importa na prática clínica gestáltica. 
As múltiplas possibilidades de pensarmos a clínica produzem formas distintas de atuação. Porém, esse não é um aprendizado que se constrói sem envolvimento. (p. 39)

Muitas vezes, na ânsia dos grandes acontecimentos, desprezamos os pequenos encontros. Assim, prestar atenção aos pequenos movimentos, pode nos dar mais sustentação para intervir. (p. 41)

Assim, os pequenos acontecimentos promovem o diálogo. . . . Portanto, cada momento traz em si uma singularidade, que deve ser acolhida com delicadeza. (p. 42)

. . . numa prática gestáltica não podemos perder de vista o sentido do vivido, seja na plenitude do encontro, seja na escuta atenta e, muito menos, reduzir o vivido à inércia do fato. $O$ como fazer [grifo da autora] é, portanto, uma descoberta que se faz no encontro. (p. 46)

Tomando distância de perspectiva identitária e patologizante, penso o atendimento psicológico como oportunidade para aprender a conhecer, conhecer-se pelo fluir de sensibilidades no Encontro, fazendo proliferar outras sensibilidades. O pedido por atenção $\mathrm{dx}$ cliente nem sempre vem configurado como um pedido por cuidados, pois aquelx que vem em busca do atendimento psicológico pode não estar aware de sua necessidade atual, ou de que pode pedir ajuda a alguém. Em outro trabalho (Soares, 2011) apontei que entendo a Gestalt-terapia como um fazer muito mais ético do que técnico, pois se fundamenta e se faz pelos fluxos de disponibilidade, mutualidade e sensibilidade para estar com x outrx na produção de um encontro único e irrepetível. Ao produzir Plantão na perspectiva gestáltica, entendo que estamos problematizando a realidade vivida pelo sujeito naquele momento, como esta por elx é percebida, focalizando seus modos de existir, e como isso engendra a criação de realidades, a partir da própria realidade pontual que se formula pela dialogicidade na relação com x psicólogx/estagiárix ali e então. Quanto a isso, recorro a Prestrelo (2000):

Ao ressignificar a experiência atual, tendo identificado a necessidade primordial à qual se relaciona essa forma de estarno-mundo aqui e agora, contextualizando-a em sua funcionalidade, ou a falta desta, posso então reconfigurar o que vivo e descobrir novas formas de lidar com o que preciso no momento - de forma atualizada e criativa. (p. 5).

Beisser (1980) denominou de Teoria Paradoxal da Mudança ao modo gestáltico de compreender os movimentos da pessoa que busca ajuda psicológica, acompanhando-a e encorajando-a a ser o que pode ser naquele momento específico no encontro clínico, mergulhando em 
sua experiência no aqui-e-agora. Em suas palavras: ". . . a mudança ocorre quando uma pessoa se torna o que é, não quando tenta converter-se ao que não é [grifo do autor]." (Beisser, 1980, p. 110). Elaborada a partir da prática clínica desenvolvida pelo casal Perls, a teoria de Beisser propõe que: ". . . os mesmos princípios são igualmente relevantes para a mudança social, que o processo de mudança individual nada mais é do que um microcosmo do processo de mudança social." (Beisser, 1980, p. 114). O autor finaliza seu texto afirmando a condição de fazer político e social das estratégias desenvolvidas por Fritz Perls para as práticas gestálticas: "Elas são aplicáveis, . . . à organização da comunidade, ao desenvolvimento da comunidade e a outros processos de mudança coerentes com o quadro político-democrático." (Beisser, 1980, p. 114). Entendo que os Perls já anunciavam os fundamentos de práticas que chamamos hoje como 'clínica ampliada', conforme fala Beisser (1980).

Se, gestalticamente, entendemos que somos subjetivações produzidas em nossas conexões com o mundo, portanto, não é possível um fazer gestáltico que isole o sujeito de seu mundo. Trago Fritz Perls (1977) para compor esse diálogo:

O estudo do modo que o ser humano funciona no seu meio é o estudo do que ocorre na fronteira de contato entre o indivíduo e seu meio, é neste limite de contato que ocorrem os eventos psicológicos. Nossos pensamentos, ações, comportamentos e nossas emoções são nossa maneira de vivenciar e encontrar esses fatos limítrofes. (p. 31).

O Plantão gestáltico consiste numa prática de clínica ampliada por expandir a noção de fazeres dx psicólogx para além da psicoterapia, sem, no entanto, negá-la como prática necessária. Expande também as experiências do fazer clínico no aqui-e-agora, problematizando o que vem a ser compreensão, intervenção, escuta, acolhimento e disponibilidade, por exemplo.

No Plantão como 'invençãoCOM' (Soares, 2017), a psicologia 'do entre' torna-se figura problematizando a psicologia 'do outro' (Soares, 2017), vigente na graduação em Psicologia. Nesta concepção de inspiração moderna $x$ psicólogx, ou $x$ estagiárix de Psicologia, tenta produzir uma prática psicológica voltada para ouvir alguém e falar-lhe numa perspectiva individualizada, identitária, recortada da noção de campo, a fim de chegar a um entendimento clínico marcado pelo poder $\mathrm{dx}$ especialista, que desqualifica a condição do sujeito de produzir conhecimento sobre si no mundo a partir de suas experiências COM 0 mundo $e$ com $x$ psicólogx/estagiárix naquele específico momento. Nas práticas gestálticas, cada atendimento pode operar a criativa construção de uma realidade singular, ali e então, de modo que a vida possa ser 
vivível num único momento, momento único, que nos remete às noções de transitoriedade e da finitude, inerentes à condição humana. Vem a fala de Laura Perls:

A verdadeira criatividade, em minha experiência, está inextricavelmente vinculada à conscientização da mortalidade. Quanto mais aguda for essa conscientização, maior será o anseio impulsivo de realizar algo de novo, de participar na infinitamente contínua criatividade na natureza. . . . É isso que torna vida vivível ... (Perls, L., 1980, p. 180).

Lembro que Fritz Perls difundiu a abordagem gestáltica em workshops terapêuticos sem o compromisso de continuidade, e Laura Perls notabilizou-se pela posterior expansão dos trabalhos gestálticos em sessões continuadas de psicoterapia bipessoal. Não estaremos atualmente precisando ampliar nossas práticas gestálticas para a clínica das urgências e dos pedidos de ajuda, e por atenção pontual? Ao disponibilizarmo-nos ao acolhimento às urgências e aos pedidos de atenção pontual por ajuda psicológica, podemos estar mais sensíveis e disponíveis às descontinuidades, desobedecendo a lógica de estabelecer nossos fazeres clínicos unicamente nas práticas de psicoterapia, supostamente mais eficazes por serem prolongadas. Praticando a Abordagem Gestáltica, que veio ao mundo desobediente, criando mundos e fazeres clínicos desobedientes, estejamos atentos aos movimentos que fazemos e aos fluxos de afetos que vivemos, que configuram nossas relações - a tudo que nos conecta de maneira reticular a outrxs humanxs e não humanxs que compõem a heterogeneidade das configurações das realidades que nos fazem e que ajudamos a fazer.

Assim, o Plantão Psicológico Gestáltico se constitui como prática tecida em fios de afetos, sensibilidades, responsabilidades e de consistência teórica - no sentido de que vem buscando responder às convocações do contemporâneo -, ampliando e fortalecendo as conexões entre os campos da clínica e do social, fazendo proliferar outras versões de realidade através do mútuo suporte, e de modos de resistir ao que nos oprime e que nos faz impotentes.

\section{Portanto, o que o SPA e o Plantão Gestáltico vêm performando?}

O Plantão Gestáltico tem feito emergir temas até então naturalizados, como: o que é acolher?; o que é efetivamente realizar atendimento psicológico?; o que é ajuda psicológica?; que realidade clínica o Plantão vem produzindo?; como vem interferindo na formação dxs 
alunxs?; o que forma, transforma, o que tira da $f(\hat{o}) r m a$ (Soares, 2009)?

Gomes e Souza (2015) apontam a prática do Plantão Psicológico como clínica que: ". . . funciona segundo as regras do imprevisível, do inesperado." (p. 172). Essa é uma das maneiras de efetuar práticas de acolhimento na graduação sem uma $f(\hat{o}) r m a$ prévia: poder fornecer atenção psicológica a quem vem buscar atendimento psicológico sem expectativas maiores, além de ser escutadx e receber ajuda em forma de atenção, amparo, orientação e encaminhamento. Poder vivenciar o espanto, o surpreender-se, 0 frustrar-se, compõe o percurso dx estagiárix plantonista e o meu como supervisora. Tornar-se plantonista não se resume a dedicar blocos de horários semanais ao SPA, esperando a chegada de pessoas em condição de sofrimento, manifestando pedido de atendimento urgente: é um processo de dedicar-se a aprender a estar disponível ao encontro com alguém em sofrimento ou em solicitação de atenção pontual; dedicar-se a viver um momento único, que pode ser inclusive, um único atendimento a essa pessoa. Chamar essa experiência de descontínua remete a uma desvalorização desta prática, contrastando necessariamente com o padrão que institui a continuidade como única e válida possibilidade de prática clínica psicológica.

Portanto, múltiplas realidades acadêmicas são performadas com o Plantão: uma clínica ampliada, por sua condição de despatologização, tornando os serviços de Psicologia mais acessíveis e flexíveis, sem necessariamente desembocarem numa psicoterapia; promove, portanto, um descentramento nxs alunxs/clientes e nxs estagiárixs, que passam a perceber que nem só a psicoterapia atende às demandas de atenção a um pedido de ajuda devido a um sofrimento; um descentramento nxs estagiárixs plantonistas, que se lançam aprendizes de um fazer que vive nas instabilidades e que pode alcançar estabilizações provisórias e, nem por isso, menos transformadoras; a discussão do que é urgência, emergência, crise, em diferentes abordagens clínicas praticadas nos campos de estágio da clínica-escola; um modo de escuta aos modos de como a educação se faz nesta IES. Uma Psicologia mais acessível? Sim, uma Psicologia de portas abertas às salas de aula, e que é percebida por docentes de outros cursos como possibilidade de acolhimento às urgências de alunxs e funcionárixs da IES. Por tudo isso, o Plantão vem evidenciando a relevância do pesquisar na clínica-escola, fazendo da clínica, pesquisa.

Tendo como viés político, da minha ação como docente e supervisora, as noções de pluralidade da condição humana e a indeterminação dos processos experienciais do existir, ouso afirmar que o Plantão Gestáltico engendra a produção de uma política ontológica, criando problematizações, inquietações, desnaturalizações, deslocamentos e, 
assim, contribuindo para performar uma realidade revitalizada e diversa dos fazeres clínicos na graduação em Psicologia. No Plantão, quem busca atenção e/ou ajuda psicológica pontual, bem como quem se dispõe a estagiar na oferta de atenção/ajuda pontual a quem a busca, sai de uma condição previamente estabelecida e naturalizada do que devem ser as falas e as atitudes de duas pessoas num atendimento psicológico. Portanto, o Plantão pró-move resistência à normatividade que ainda constitui muitos fazeres na academia. Encontro suporte em Arendt e Moraes (2013) que, inspirados em Annemarie Mol, indicam:

São necessárias novas estratégias metodológicas para lidar com o passageiro, o distribuído, o múltiplo, o não causal, o caótico, o complexo. . . . A nova orientação é, assim, uma nova política de intervenção, uma política ontológica. Juntar estes termos - política e ontologia - significa dizer que a realidade é efeito, é 'performada'. Significa também dizer que o que conta como realidade envolve negociação e trabalho. (p. 316).

Mais adiante, os autores comentam que: ". . . é perturbadora qualquer concepção de vida que a afaste dessa dimensão de experimentação, de tateio, de reinvenção das suas próprias normas." (Arendt \& Moraes, 2013, p. 320).

Avançando na discussão da perspectiva política dos fazeres no Plantão Psicológico, trago a contribuição de Souza e Farias (2015): ". - . no processo de intervir psicologicamente está implícita a associação do sujeito psicológico ao sujeito político, visto que a escuta clínica se revela enquanto atitude ética e política diante do ser. Portanto, facilitar mudanças, é sempre um fazer político." ( $p$. 24). Entendo o atendimento psicológico no SPA como prática democrática que acolhe - sem projetos normativos - aquelx que vem em busca de atenção, e que é tão pouco assistidx pelas políticas públicas de nosso país. Enfatizando o alcance social e democrático do Plantão Psicológico, volto a Freire (2003) que me confirma:

. . . é possível falar-se de Ética e de democracia nos serviços de psicologia. Estar a serviço do outro que nos procura para poder assisti-lo em seu devir-outro e escutar sua alteridade, principalmente naquilo que o fará buscar qualidade de vida para si e para os outros. Quando o outro nos procura, nada melhor que a resposta (originariamente dada à visitação do Outro, em Lévinas) 'eis-me aqui'. (p. 14). 


\section{À guisa de fechamento...}

O Plantão constitui-se um desvio no padrão de muitas das rotinas dos estágios na graduação em Psicologia. Num cenário acadêmico, Xs estudantes criam expectativas de aprender a conduzir trabalhos clínicos prolongados - aprender a tornar-se psicoterapeuta é a grande meta $\mathrm{dx}$ graduandx, pois isso implica em estar mais aptx a trabalhar ao sair da universidade -, segundo elxs próprixs. Afinal, a principal ocupação remunerada dxs psicólogxs no Brasil ainda é a clínica de psicoterapia bipessoal, em consultório particular. Cabe problematizar: aprender a dedicar-se a únicos atendimentos é promissor em termos de remuneração futura para $x$ psicólogx? Respondo que sim, pois podemos realizar atendimentos psicológicos pontuais em empresas, hospitais, consultórios de ruas, clínicas particulares, etc.

Sensibilidade é treinável? Esta é uma indagação que faço constantemente a mim mesma, a colegas docentes na graduação, nos cursos de especialização em Psicologia Clínica, nas formações de psicoterapeutas, assim como a alunxs e estagiárixs. Continuo com a indagação. Recorro novamente a Quadros (2012) e a seus próprios, e preciosos, questionamentos e reflexões em andamento:

A clínica que permite desvios, é um campo que situa-se entre afetos e afetações. É um campo em movimento e, como tal, pretende-se vivo, pulsante, não capturado nos limites das respostas enquadradas. . . 'Afinal, o que é psicologia clínica e como um psicólogo clínico se constitui?' - diria, . . . que:

. . . Clínica é articulação entre conhecimento e sensibilidade

Clínica é processo

Clínica é desvio

Clínica é inventividade

Clínica é possibilidade

Clínica é impossibilidade

Clínica é artesania

. . . , o que nos constitui como clínicos passa pela intuição, o aprendizado contínuo, o medo, a ousadia, o conflito, a rebeldia, a vivência, os obstáculos e o amor.

. . a prática clínica nos mantém em vigília, acordando e convocando todos os nossos sentidos. . . .sugerimos uma atenção pelo viés da sensibilidade. Esse é um compromisso que transcende os manuais, mas deve apoiar-se numa ética das relações. (p. 196-197).

A inventividade e a disponibilidade sem um projeto prévio de como deve ser o atendimento, nos fazem fazer uma clínica artesanalmente (Quadros, 2012). Isso é evidenciado quando nos dedicamos a um 
modo de fazer a prática clínica em um único atendimento, ou em poucos.

No decorrer de meu percurso na supervisão dxs plantonistas e nas múltiplas implicações que a condução deste projeto proporciona, venho entendendo que não há modo único de fazer o Plantão Psicológico Gestáltico, o que faz dele uma clínica da diversidade, da inclusão, uma clínica de possibilidades ampliadas. Este Plantão Gestáltico, feito no SPA, tensiona, problematiza e fortalece as conexões entre a clínica e a educação. Por ser um campo de estágio e pesquisa, suscita a urgência de discutirmos o SPA na graduação em Psicologia como um espaço de escuta institucional. No caso específico deste SPA, o Plantão trouxe para o plano figural as práticas psicológicas performadas pelas afetações criadas pelas mudanças metodológico-educacionais da IES - temos um singular cenário institucional em que práticas educacionais contribuem para inventar uma clínica e vice-versa, afetando usuárixs, estagiárixs, supervisorxs, coordenadoras, demais professorxs da IES e as recepcionistas. Este Plantão Gestáltico vem acolhendo predominantemente, até 0 presente momento, os sentidos do vivido pelxs alunxs da IES, escutando os modos como se tem feito educação e como essxs actantes dos fazeres institucionais podem ser compreendidos em seus sonhos, sofrimentos, frustrações e vitórias. É 'o pequeno falando do grande', ou seja, a pessoalidade dando voz aos múltiplos coletivos de que cada pessoa participa e transforma.

Fazemos uma Psicologia Clínica efetivamente social, ao marcarmos a conexão entre campos de conhecimento e de fazeres que não podem ser colocados em perspectivas opostas. Arendt e Moraes (2013) voltam a esclarecer o que é um fazer eminentemente social em Psicologia: ". . . o social que se associa à expressão 'psicologia social' não é algo dado de antemão . . . O social é verbo, é ação situada ação que se produz nas práticas cotidianas, aí incluídas, sem dúvida, o fazer da psicologia. (p. 321).

O Plantão, promovendo encontros de produção de sentido para todxs que o 'fazem' acontecer, produz uma política ontológica (Mol, 2008), favorecendo modos de existir conscientes, cooperativos e criativos. Com Mol, afirmo que os fazeres gestálticos produzem uma política ontológica ao constituírem-se como modos de subjetivação, criando realidades existenciais, criando-se como clínica crítica de seus próprios fazeres a cada momento.

Souza e Farias (2015) apontam que facilitar mudanças é sempre um fazer político, afirmando o Plantão Psicológico como Clínica Ampliada: ". . clínica democrática, expansiva, plástica, flexível e que considera a realidade experiencial do demandante nas várias dimensões que são contempladas pelos sujeitos ..." (p. 25).

Encaminho o encerramento desta escrita lembrando que, estando gestalticamente de Plantão, fazemos uma Psicologia ética e 
politicamente encorpada, uma prática sensível, implicada com realidades acadêmicas inclusivas e democráticas pelo acolhimento a quem chega pedindo atenção. Ao estarmos de Plantão, incluímos os processos de conscientização, as curiosidades, os riscos, as inseguranças e o engajamento dxs plantonistas e da supervisora. A aprendizagem da disponibilidade para o atendimento psicológico esse encontro com o imponderável - é um aprender a atender sem esperar com isso ser atendidx em suas ansiedades de aprendiz e/ou de docente. Entendo que estar gestalticamente de Plantão é estar a serviço do indeterminado que vai nos fazer crescer, por nos dispormos a movimentos ainda não experimentados. Politicamente posicionadxs, nos questionamos permanentemente: 'Que psicologia fazemos quando dizemos que fazemos Psicologia?'

Plantão não é especialidade - é prática de atendimento psicológico pontual. Sendo o acolhimento pela compreensão uma necessidade contemporânea, penso que na Abordagem Gestáltica precisamos expandir nossas práticas para além da psicoterapia. Portanto, o Plantão vem contemplar a demanda por atenção psicológica pontual, em diferentes espaços e contextos - atenção especialmente aos fazeres na formação universitária.

\section{Referências}

Adichie, C. N. (2009). O perigo de uma história única [Canal de YouTube TED Ideas Worth Spreading]. Recuperado de https://www.youtube.com/watch?v=D9Ihs241zeg\&t=221s

Arendt, R. J. J., \& Moraes, M. O. (2013). Contribuições das Investigações de Annemarie Mol para a Psicologia Social. Psicologia em Estudo, 18(2), 313-321. doi: 10.1590/S141373722013000200012

Beisser, A. (1980). A teoria paradoxal da mudança. In J. L. Fagan \& I. L. Shepherd (Eds.), Gestalt-terapia - teoria, técnicas e aplicações (pp. 110-114). Rio de Janeiro, RJ: Zahar Editores.

Buber, M. (2017). O caminho do homem segundo o ensinamento chassídico. São Paulo, SP: Editora Realizações.

Campos, A. F., \& Daltro, M. (2015). A clínica ampliada no enfoque da Gestalt-terapia - um relato e experiência em supervisão de estágio. Revista Psicologia, Diversidade e Saúde, 4(1), 59-68. doi: 10.17267/2317-3394rpds.v4il.743

Freire, J. C. (2003). A Psicologia a Serviço do Outro: Ética e Cidadania na Prática Psicológica. Psicologia Ciência e Profissão, 23(4), 12-15. doi: 10.1590/S1414-98932003000400003

Gomes, A. G. L., \& Souza, S. (2015). Conhecendo a experiência do plantonista no serviço de plantão psicológico em hospital geral. In S. Souza, F. B. Silva Filho \& L. A. de A. Montenegro (Eds.), 
Plantão psicológico: ressignificando o humano na experiência da escuta e do acolhimento (pp. 155-178). Curitiba, PR: Editora CRV.

Guedes, A., Almeida, H. M. E., Bianchi, I. F. S., Ribeiro, M. F. R., Cunha, V. L., \& Kairós Assessoria Psicológica. (1981). A consulta avulsa. São Paulo, SP: Departamento de Gestaltterapia do Instituto Sedes Sapientiae de São Paulo.

Mol, A. (2008). Política Ontológica. Algumas ideias e várias perguntas. In J. A. Nunes \& R. Roque (Eds.), Objectos Impuros: Experiências em Estudos sobre a Ciência (pp. 1-24). Porto: Edições Afrontamento.

Moraes, M. O. (2010). PesquisarCOM: política ontológica e deficiência visual. In M. O. Moraes \& V. Kastrup (Eds.), Exercícios de ver e não ver: arte e pesquisa com pessoas com deficiência visual (pp. 26-51). Rio de Janeiro, RJ: Nau Editora.

Morato, H. T. P. (1987). Abordagem Centrada na Pessoa: teoria ou atitude na relação de ajuda? In R. L. Rosenberg (Ed.), Aconselhamento psicológico centrado na pessoa (pp. 24-44). São Paulo, SP: EPU.

Perls, F. S. (1977). A Abordagem gestáltica e a Testemunha Ocular da Terapia. Rio de Janeiro, RJ: Zahar Editores.

Perls, L. (1980). A abordagem de um Gestalt-terapeuta. In J. L. Fagan \& I. L. Shepherd (Eds.), Gestalt-terapia - teoria, técnicas e aplicações (pp. 174-180). Rio de Janeiro, RJ: Zahar Editores.

Prestrelo, E. T. (2000). Como ser um sobrevivente ou, como lembrar onde guardamos nossa alma. Comunicação Oral em Tema Livre no VII Congresso Internacional de Gestalt-terapia, Rio de Janeiro, RJ, Brasil, 7.

Quadros, L. C. T. (2012). Desafios da prática clínica na formação de psicólogos: revendo fronteiras e criando possibilidades. IGT na Rede, 9(17), 187-199. Recuperado de http://www.igt.psc.br/ojs/

Quadros, L. C. T. (2014). O cotidiano de uma Gestalt-terapeuta: a clínica dos pequenos acontecimentos. In E. T. Prestrelo \& L. C. T. Quadros (Eds.), O tempo e a escuta da vida: configurações gestálticas e práticas contemporâneas (pp. 37-50). Rio de Janeiro, RJ: Quartet.

Rebouças, M. S. S., \& Dutra, E. (2010). Plantão psicológico: uma prática clínica da contemporaneidade. Revista da Abordagem Gestáltica, 16(1), 19-28. Recuperado de http://pepsic.bvsalud.org/scielo.php?script=sci_arttext\&pid=S1 809-68672010000100004

Schmidt, M. L. S. (1987). Aconselhamento psicológico: questões introdutórias. In R. L. Rosenberg (Ed.), Aconselhamento psicológico centrado na pessoa (pp. 14-23). São Paulo, SP: EPU. 
Souza, S., \& Farias, A. E. M. (2015). Plantão psicológico: a urgência da acolhida. In S. Souza, F. B. Silva Filho \& L. A. Montenegro (Eds.), Plantão psicológico: ressignificando o humano na experiência da escuta e do acolhimento (pp. 15-32). Curitiba, PR: Editora CRV.

Soares, L. L. M. (2009). A Gestalt-terapia na universidade: da f(ô)rma à boa forma. Estudos e Pesquisas em Psicologia, 9(1), 150-161. Recuperado de http://pepsic.bvsalud.org/scielo.php?script=sci_arttext\&pid=S1 808-42812009000100012

Soares, L. L. M. (2011). A psicoterapia com a criança, por um fio. Revista IGT na Rede, 8(14), 67-78. Recuperado de http://www.igt.psc.br/ojs/

Soares, L. L. M. (2017). O estágio básico na graduação em Psicologia: laboratório das múltiplas conexões universidademundo (Tese de Doutorado). Universidade do Estado do Rio de Janeiro, Programa de Pós-graduação em Psicologia Social, Rio de Janeiro, RJ, Brasil. Recuperado de http://www.bdtd.uerj.br/tde_busca/arquivo.php?codArquivo=1 1910

Soares, L. L. M. (2019). A psicoterapia gestáltica como prática política. In D. M. Silva \& C. M. Alegria (Eds.), Percursos terapêuticos no contexto clínico e social (pp. 97-104). Curitiba: Juruá Editora.

Tassinari, M., \& Durange, W. (2019). Clínica da urgência psicológica: a radicalidade do encontro como processo de promoção de saúde. In M. Tassinari \& W. Durange (Eds.), Plantão e a clínica da urgência psicológica (pp. 43-60). Curitiba, PR: Editora CRV.

\section{Endereço para correspondência Luciana Loyola Madeira Soares \\ Rua José Higino, 282, ap. 101, Tijuca, CEP 20520-202, Rio de Janeiro - RJ, Brasil Endereço eletrônico: psi.lucianasoares@gmail.com}

Recebido em: 13/10/2019

Reformulado em: 22/01/2020

Aceito em: 23/01/2020

\section{Notas}

* Psicóloga (UERJ), Mestre (UVA), Doutorado (PPGPS - UERJ). Gestalt-terapeuta. Professora, supervisora, pesquisadora do UCL. Especialista em saúde mental Infanto-juvenil, PUC Rio. Especialista em Psicologia Clínica e em psicologia Educacional, CRP RJ.

${ }^{1} \mathrm{O}$ "X" é uma opção para abranger igualmente os diversos gêneros.

2 Inspirado em PesquisarCOM de Moraes (2010).

${ }^{3}$ Inspiração em Adichie (2009). 
Este artigo de revista Estudos e Pesquisas em Psicologia é licenciado sob uma Licença Creative Commons Atribuição-Não Comercial 3.0 Não Adaptada. 